\title{
Reflexiones en torno a la traducción de la oración atributiva árabe al español
}

\author{
ABDERRAHIM AARAB \\ Universidad de Granada \\ aarababdel@yahoo.fr
}

Recibido: 27 de noviembre de 2012

Aceptado: 20 de marzo de 2013

\section{RESUMEN}

En el presente artículo nos proponemos llevar a cabo un estudio práctico en torno a la traducción de la estructura atributiva árabe y sus variantes sintácticas con 'inna y kāna. Para nosotros, la sintaxis presenta serios problemas en la operación traductora, puesto que cada lengua dispone de sus propios procedimientos de construcción y estructuración que dificultan la tarea del traductor. En este sentido, vamos a estudiar el concepto de atribución en las gramáticas española y árabe, con la finalidad de buscar las equivalencias y divergencias entre la oración atributiva árabe y española para ponerlas al servicio de la traducción entre las dos lenguas.

Palabras clave: traducción, sintaxis comparada, oración atributiva, equivalencia estructural.

On the translation of the attributive sentence from Arabic into Spanish

\begin{abstract}
In this paper, we propose to study the translation of the Arabic attributive structure and its syntactic variants 'inna y kāna. For us, syntax causes serious problems in the translation process, since each language has its own building and structuring procedures that hinder the task of the translator. In this sense, we will study the concept of attribution in the Spanish and Arabic grammar in order to find the equivalences and differences between Arabic and Spanish attributive sentence, and therefore make them available to the task of translation in the two languages.
\end{abstract}

Keywords: translation, comparative syntax, attributive sentence, predicative sentence, structural equivalence.

Sumario: 1. Introducción. 2. La oración del mubtada' y al-jabar. 3. Equivalencias estructurales. 4. Práctica de traducción. 5. Conclusión. 


\section{Introducción}

Actualmente, la traducción se considera como una de las disciplinas más importantes y relevantes en el ámbito lingüístico gracias al desarrollo y evolución espectaculares que esta actividad ha experimentado en la segunda mitad del siglo XX, tal y como afirma el historiador Ballard (1988:10).

Así, han aparecido muchas escuelas y enfoques que, desde sus diferentes perspectivas y puntos de vista, se han prestado a estudiar y reflexionar en torno a esta actividad, con el fin de sentar los fundamentos teóricos de la disciplina. Uno de los enfoques más importantes y destacados en la reflexión teórica sobre la traducción, es el enfoque lingüístico, cuyas propuestas y postulados se inspiran en los principios y teorías de la lingüística moderna, tal como sostiene Hurtado Albir (2001: 126): «Se trata de enfoques basados en la aplicación de determinados modelos procedentes de la lingüística y que inciden en la descripción y comparación de lenguas».

En este sentido, los representantes de la lingüística moderna, con sus diferentes tendencias (generativismo, estructuralismo, funcionalismo, etc.) han contribuido notablemente al desarrollo del pensamiento teórico acerca de la traducción. En esta línea, cabe mencionar los trabajos de Nida y Taber (1969) de orientación funcionalista, junto a Catford (1965) (citado por Valero Garcés 1996: 194).

De este modo, a partir de la noción de "equivalencia" los lingüistas han definido la operación traductora que, para ellos, debe tener como fin la equivalencia entre el texto original (TO) y texto meta (TM) (García Yebra, 1983: 59). Sin embargo, en determinados planos como la sintaxis, dicha equivalencia es mucho más difícil y los problemas de traducción escrita ${ }^{1}$ se plantean con todo su peso y su complejidad, como sostienen algunos lingüistas (Mounin 1977: 287). De ahí, nuestra convicción de la importancia vital que adquieren los trabajos cuyo objeto de estudio es la comparación de la sintaxis de LO y LM, caso del presente trabajo entre el árabe y el español, mediante el cual pretendemos sacar conclusiones y evidencias que faciliten la labor del investigador en torno a la estructura atributiva y su traducción del árabe al español.

\section{La oración del mubtada' y al-jabar}

\subsection{Elementos constituyentes}

La oración nominal del árabe tiene como elementos constituyentes esenciales almubtada' y al-jabar que funcionan, respectivamente, como musnad ilayhi y musnad. La gramática árabe llama a este tipo de oraciones إنْيِية (nominales), dado que empiezan con إن إن (nombre) y se oponen a las verbales, que empiezan con un verbo, tal

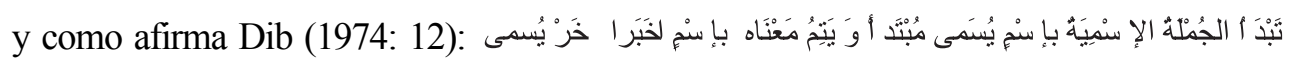

\footnotetext{
1 Con este término nos referimos a la traducción escrita de un texto escrito. Ver HuRTADO ALBIR (2001:70).
} 
(La oración nominal empieza con un nombre, llamado al-mubtada'y alcanza su pleno sentido con otro nombre, denominado al-jaba).

Además, como podemos comprobar a través de la traducción de una oración del tipo (1) (El chico es pequeño) (Paradela Alonso 2002: 62), la estructura equivalente a una nominal árabe en la lengua española es una oración atributiva ${ }^{2}$ con el verbo ser. Por lo tanto, de ahora en adelante utilizaremos el término «atributiva» para referirnos también a la oración nominal del mubtada'y al-jabar.

\subsubsection{Al-mubtada'}

Es el segmento que equivale al sujeto de la oración atributiva del español. En esta posición suelen aparecer palabras simples de la categoría de un sustantivo, sea en forma de nombre propio: مُحَّدّ ناجِ (2) (Mohammed está aprobado) ('Ubada s.a: 56 ), o de pronombre personal o demostrativo:<smiles>[Mg][Mg][Mg][Mg]</smiles>

Él está en la isla. (Palacios 1959: 77).

(4) هَا هُوَ الحَقُ

Esto es la verdad. (Blanco 1891: 107).

Pero, también, el sustantivo en su forma de palabra simple puede ser un nombre

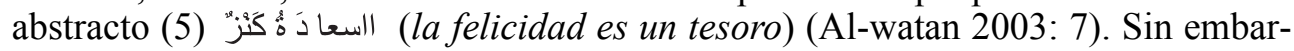
go, en la posición de un mubtada' no siempre aparecen palabras simples, sino que en muchos casos aparecen sintagmas más complejos que desempeñan la misma función. De este modo, al-mubtada' para el gramático Ibrahim 'Ubāda (s.a: 56) puede adoptar las siguientes formas sintácticas:

- un sintagma nominal de iḍ̂afa:

- un sintagma nominal de relativo:

- un sintagma nominal de partícula:

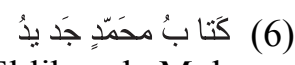

El libro de Mohammed es nuevo.

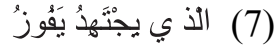

El que se esfuerza gana.

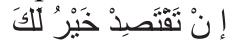

Así, en la oración del primer ejemplo de 'Ubāda, vemos cómo al-mubtada' se presenta bajo forma de un sintagma nominal de $i d ̣ a \bar{f} a$, formado por dos nombres yuxtapuestos. Estos nombres reciben, respectivamente, la denominación sintáctica

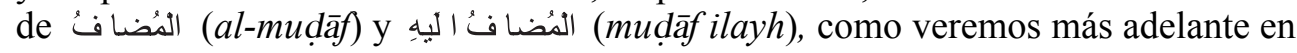
detalle. Además, estos sintagmas pueden estar compuestos por más de dos elementos en oraciones en las que el sintagma de $i d ̣ a \bar{f} a$ en función de mubtada' está com-

2 Este nombre lo hemos dado a la oración nominal del árabe siguiendo a BLANCO (1891: 95), quien califica al jabar de atributo. 
puesto por tres elementos, así como en سنَار آ تُ رَئيس الجا مِعَةِ بَيْضاءُ (9l coche del rector de la universidad es blanco) (Paradela Alonso (2002: 32).

En la oración (7) el mubtada' es un sintagma relativo, formado por el relativo nominal al-laḍ̄ (quien) junto al verbo. Este mismo sintagma puede aparecer integrado por otro tipo de relativo que es una partícula, a la que la gramática árabe da el nombre de mausūl harfi (relativo de partícula) ن ( 'in), como se refleja en la oración (8).

Por otra parte, en lo que concierne a la determinación del mubtada' es preciso señalar que éste tiene que estar en principio definido, siempre cuando no se representa bajo la forma de un nombre propio. Pero en los demás casos en los que el mubtada' es un sustantivo tiene que estar forzosamente definido. De este modo, la determinación en árabe se realiza mediante al-alif con wasla que funciona como el artículo determinado, equivalente al artículo el del español. Pero, a diferencia de este último, el artículo definido en la lengua árabe va unido al nombre a modo de un prefijo. Además, es invariable en cuanto al número y género del sustantivo, como en la siguiente oración: 'البَيْتُ صَنير (10) (La habitación es pequeña) (Haywood y Nahmad 1992: 30).

Por otro lado, el gramático Al-sanŷurŷ̄ (1976: 223) al hablar de las características gramaticales del mubtada' expone las situaciones en que este último aparece indefinido, y esto ocurre cuando se encuentra compuesto por dos palabras o nombres sucesivos y relacionados por la partícula g (waw al-'atf) (de coordinación),

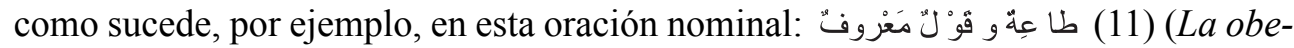
diencia y el consejo son un bien).Y, por último, cuando al-mubtada' aparece precedido del prefijo لا مُ الإبتِّداء (lam al-ibtida'), como en (12) (El hombre está enfermo).

Finalmente, hay que señalar que al-mubtada', en algunas situaciones, puede ser implícito sobre todo cuando la oración atributiva se expresa en pasado, así como en la oración كان كريما (Era generoso) (Al watan 2003:12).

\subsubsection{Al-jabar}

Esta unidad equivale al atributo de la oración española; en la mayoría de los

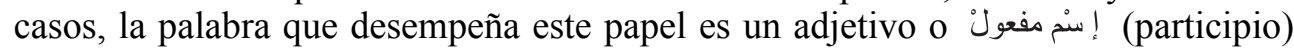
(Blanco, 1891: 127):

(13)

La noche está fría.

(14) هؤ لاء الر جالُ مَشَغو لو نَ في مَكا تِبهُنْ

Estos hombres están ocupados en sus despachos (Cowan 1998: 117).

Pero también este segmento puede ser un nombre, como en la oración العِنَبُ فا كِهَة (15) (La uva es una fruta) (Al watan 2003:12). 
Sin embargo, al igual que al-mubtada', al-jabar no siempre está constituido por una palabra simple, sino que en muchos casos puede tener varias formas sintácticas, como especifica 'Ubāda (s.a: 56) en los siguientes ejemplos:

- una oración verbal:

- una oración nominal:

- sintagma nominal de iḍāfa:

- cláusula nominal:

- sintagma de iḍāfa formal ${ }^{4}$ :

- sintagma relativo de partícula:

- sintagma adverbial:

- sintagma preposicional:

- sintagma nominal de tamyīz:

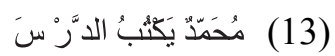

Mohammed escribe la lección.

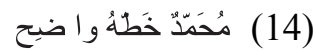

La escritura de Mohammed está clara. (Mohammed, su escritura está clara) ${ }^{3}$ (15) مُحَمَّد أ خُو عَلِيَ

Mohammed es el hermano de Ali. (16) مُحَدَّ وأ ضِيح خَطَه

La escritura de Mohammed es clara (Mohammed, clara es su escritura). (17) مُحَمَُّ وا ضِحِح الخَطِ

Mohammed es de clara escritura.

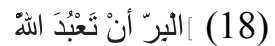

La virtud es adorar a Dios. (19)

Mohammed está en nuestra casa. (20) مُحَمَّد في المَنْجَدِ

Mohammed está en la Mezquita.

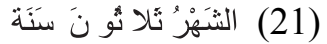

El mes es treinta días.

Pues, así, queda muy claro que la naturaleza gramatical del jabar es muy variada y que va desde una simple palabra hasta unas estructuras más complejas, a modo de sintagmas u oraciones.

Por otra parte, Paradela Alonso (2002: 152) añade a las formas complejas del atributo la que tiene como núcleo un nombre acompañado de un sintagma relativo,

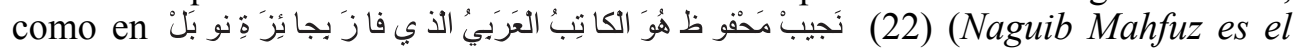
escritor que ganó el premio Nobel).También pone de manifiesto las formas del atributo en su faceta de complemento preposicional الجارُو المَجرور (ŷar wa maŷrur)o adverbio de lugar. Cuando se dan estos casos, el atributo suele anteponerse al-mub-

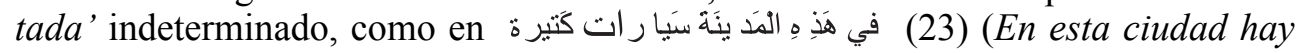

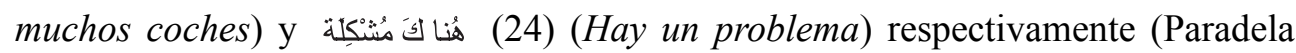
Alonso 2002: 66).

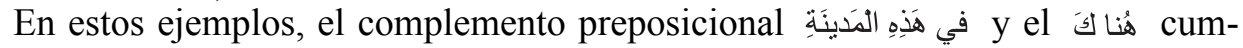
plen la función del jabar antepuesto al mubtada'. Al igual que en los casos anteriores, al-jabar también precede al mubtada' en el «caso de oraciones que expresan

\footnotetext{
${ }^{3}$ Las oraciones puestas entre paréntesis son traducciones literales al español, mediante las cuales pretendemos reflejar el orden de palabras de las oraciones árabes.

4 Esta denominación es de PARAdela Alonso (2002: 36).
} 
mandato, consignas, prohibiciones, etc.» (Paradela Alonso 2002: 67). Así, como en estas oraciones donde las palabras sis

(25) (للأ طفال

Prohibido fumar.

(26) مَنَو ع الو قو فَُ هُنا

Prohibido detenerse aquí.

(27) مَسْوَ حُ الدُّخو لُُ للأطفال

La entrada está permitida a los niños.

En la misma línea, el autor Hasan (1975: 466) en su estudio de las formas sintácticas del atributo resalta que éste puede ser a su vez una oración nominal o ver-

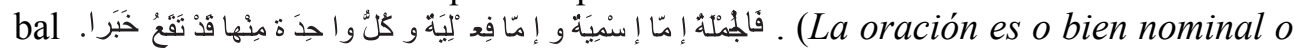
bien verbal, y cada una de ellas puede ser un atributo). Así, como en las siguientes oraciones (Hasan 1975: 16):

(28) الثَتِاء يُقَسو بَرْ دُهُ

El frío del invierno se endurece.

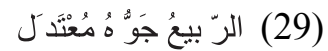

El clima de primavera es moderado.

Así se ve que en la oración del primer ejemplo al-jabar es una oración verbal,

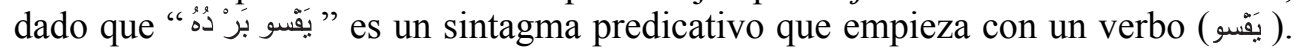
Por otro lado, en el segundo ejemplo, al-jabar es una oración nominal, ya que

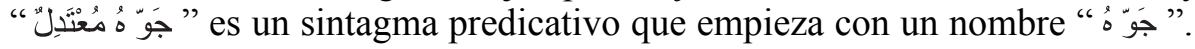

A estas dos estructuras atributivas en las que el atributo es una oración, la gramática árabe las denomina oración compuesta o كبّر como la define Hasan (1975: 16)

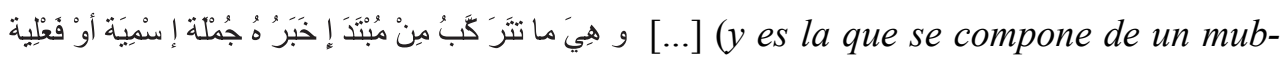
tada' cuyo jabar es una oración verbal o nominal).

Asimismo, Hasan (1975: 16) denomina a esta oración verbal o nominal que desempeña la función de atributo الجُملة الصُغرى (al-ŷumla al-sugra), que desde el punto de vista sintáctico está subordinada al mubtada' de la oración nominal compuesta. Ahora bien, hemos visto que el atributo o al-jabar puede representarse bajo forma de una oración nominal, lo que significa también que se compone a su vez de un mubtada'y de un jabar. Cuando se da este caso, al-mubtada' de la oración nominal subordinada, se caracteriza especialmente por llevar un pronombre afijo unido a él $(\bullet)$, que concuerda en número y género con el mubtada' de la oración compuesta. Recordemos la oración del ejemplo (29), donde el mubtada' de la oración subordinada es " qجوَهُ que aparece acompañado por este pronombre afijo que específicamente hace referencia al mubtada' de la oración compuesta o al-kubra, es decir, al " (primavera). Esta norma es aplicable también a la oración subordinada verbal en función de atributo, pero en este caso el pronombre afijo va unido al segmento cuya función sintáctica es un sujeto de dicha oración verbal, como en “ “ بَرْ دُ " en la ora- 
ción (28). Asimismo, cabe subrayar que una oración verbal subordinada en función de jabar no siempre está compuesta por un verbo y su sujeto, sino que en muchos

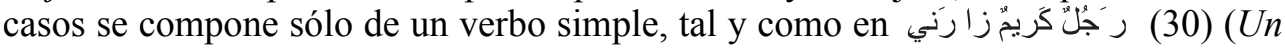
hombre noble me ha visitado). (Veccía 1961: 183)

Con esto, asistimos en realidad a un mecanismo muy peculiar y propio en la construcción de las atributivas del árabe, que difiere radicalmente de los mecanismos de construcción de las mismas oraciones en la lengua española.

Por otro lado, en lo que se refiere a la determinación del jabar, cabe señalar que éste debe ir indefinido. Es decir, sin el alif que desempeña la función del artículo como hemos constatado anteriormente. De esta manera, la indeterminación de este segmento en una oración atributiva adquiere una importancia vital. Nos referimos a que, en la lengua árabe, existen unas estructuras que, desde el punto de vista estructural, disponen de una estructura similar a las oraciones nominales o atributivas. Se trata de los sintagmas calificativos que al igual que las oraciones atributivas se componen de un nombre antepuesto a un adjetivo. En este sentido, en (31)

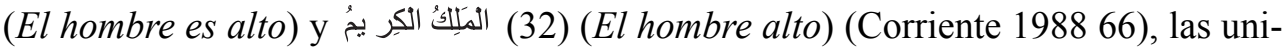
dades gramaticales son un nombre y un adjetivo, pero sólo la primera oración se considera como una atributiva, mientras que la segunda es un sintagma calificativo. De este modo, se ve que únicamente hemos logrado distinguir entre ellas por la indeterminación del adjetivo de la primera frente a la determinación del adjetivo mediante al-alif de la segunda. En consecuencia, se manifiesta el papel decisivo desempeñado por el artículo determinado ال (al-alif), como elemento determinante del carácter atributivo o nominal de una estructura, y también como elemento distintivo entre una oración nominal y un sintagma calificativo cuyas estructuras pueden producir cierta confusión. No obstante, existen algunas situaciones en las que el jabar de la oración atributiva aparece unido al artículo determinado al-alif. Cuando se da este caso, la oración atributiva tiene que llevar necesariamente un pronombre personal de la tercera persona gramatical que concuerde en número y género con el mubtada'. Este pronombre recibe en la teoría gramatical árabe la denominación de

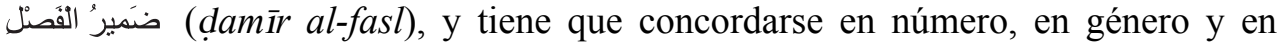
nombre con al-mubtada', como en la oración: السَيُ هُو الأسنتًاد (El señor es el profesor) (Paradela Alonso 2002: 67).

Con esto, asistimos en realidad a un tipo de oraciones nominales muy peculiares, no solamente por el hecho de llevar el pronombre personal oه como elemento esencial en su construcción, sino que también en ellas se ve determinada la naturaleza gramatical del jabar. Éste, en estas estructuras, además de estar determinado con al-alif, tiene que ser de la categoría de un sustantivo, como podemos comprobar en la siguiente cita (Blanco 1891: 107):

On ajout nécessairement, avant l'attribut, un pronom séparé de la troisième personne, s'accordant en genre et en nombre avec le sujet, lorsque cet attribut, à cause de sa forme, peut être confondu avec un substantif explicatif au un adjectif qualificatif.

(Añadimos necesariamente, antes del atributo, un pronombre separativo de tercera persona, que concuerda en género y en número con el sujeto, cuando 
este atributo, a causa de su forma, puede ser confundido con un sustantivo explicativo o con un adjetivo calificativo).

Además del pronombre personal, la oración nominal árabe puede adoptar otro segmento o palabra que puede aparecer en la posición intermedia entre $a l$ - $m u b$ tada' y al-jabar. Este es el caso de los verbos indeclinables, llamados verbos de

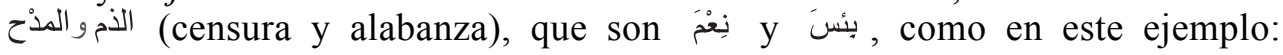

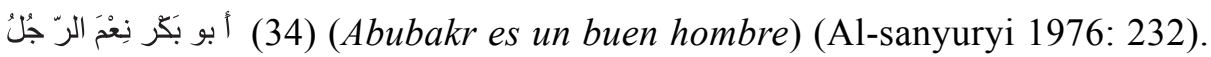

\section{Equivalencias estructurales}

\subsection{Forma compuesta}

A la luz del análisis que hemos realizado de la oración atributiva árabe, queda comprobado que presenta no pocas diferencias y contrastes con la oración atributiva española. Esto, a pesar de que estas oraciones, en determinados casos, tienen en común desde el punto de vista sintáctico la presencia de dos elementos idénticos: el sujeto y el atributo.

De esta forma, las discordancias que hemos constatado en este trabajo contrastivo se deben básicamente a la diferencia que existe sobre la noción gramatical de "atribución" en ambas gramáticas. En este sentido, comprobamos que si hay algo que caracteriza de modo peculiar a dicha noción en la gramática árabe es el hecho de incluir dentro del esquema atributivo estructuras que, en realidad, son de carácter verbal o predicativo. Hacemos referencia precisamente al tipo de oraciones nominales llamadas compuestas, cuyo atributo es una oración verbal subordinada. En estas oraciones, como hemos visto, el atributo puede tener dos formas sintácticas diferentes.

La primera forma sintáctica es cuando la función de dicho atributo se realiza por un verbo conjugado como en la oración (13), lo que da lugar a unas estructuras que desde el punto de vista sintáctico son inversas. Esta inversión afecta al verbo, dado que estas mismas estructuras tienen el orden de palabras (a) sujeto + verbo (SV), en el que el verbo aparece precedido del sujeto, que normalmente suele posponerse, tal como impone el orden sintáctico (b) verbo + sujeto (VS), predominante en le lengua árabe. De este modo, comprobamos que las estructuras de este tipo se consideran atributivas únicamente por el hecho de tener como elemento inicial un nombre. Por lo tanto, la palabra que sigue a este último tiene que ser necesariamente un atributo, incluso si éste es un verbo, conforme a las normas de clasificación y definición de las oraciones en la gramática árabe.

En consecuencia, la oración atributiva árabe cuyo atributo es un verbo conjugado puede cambiar de carácter atributivo a predicativo, solamente en función del cambio del orden de palabras. Así, se revela la diferencia radical que supone este tipo de atribución respecto a la lengua española. En esta última, una estructura atributiva se encuentra bien definida y diferenciada de una oración predicativa.

En la gramática española, cuando se distingue entre la oración atributiva y la oración predicativa se sigue el parámetro de la naturaleza gramatical del atributo. Éste 
debe ser nominal en la oración atributiva y verbal en la predicativa. Por consiguiente, una estructura atributiva en español de ningún modo puede tener un atributo en forma de un verbo conjugado, ni puede cambiar su carácter atributivo por predicativo mediante el cambio del orden de sus elementos constituyentes.

De esta manera, en nuestro propósito de hallar equivalencias estructurales en el ámbito de traducción entre las dos lenguas, constatamos que las oraciones atributivas árabes del tipo mencionado se traducen al español simplemente por las oraciones predicativas cuyo orden de palabras es SV.

En cuanto al segundo caso, cuando el atributo de la oración compuesta árabe es una oración verbal subordinada, como en la oración (28) -que se compone de un verbo y un sujeto- cabe advertir que, al igual que el caso anterior, en estas oraciones también hay una inversión de los elementos constituyentes. Pero, en este caso la inversión es mucho más complicada que en el caso anterior, lo que pone de manifiesto una forma de ordenación sintáctica muy peculiar de la sintaxis árabe. En esta línea, vemos que en estas estructuras, la inversión afecta a los elementos del sintagma de $i d \bar{a} a f a$, dado que su orden sintáctico $(\mathrm{c})\left(\mathrm{S}+\mathrm{AT}(\mathrm{v}+\mathrm{s})^{5}\right.$ es en realidad una inversión del orden sintáctico (d) $\left(\mathrm{S}(\mathrm{s} \text {. iḍāfa) }+\mathrm{V})^{6}\right.$ en el que el sujeto tiene la forma sintáctica de un sintagma de $i$ dăfa.

Así, vemos que en el orden sintáctico (c), los componentes de este mismo sintagma adquieren diferentes situaciones sintácticas, puesto que $a l$ - $m u d \bar{a} f$ (regente) pasa a cumplir la función del sujeto subordinado y al-muḍâf ilayh (regido) se convierte en al-mubtada' de la oración compuesta, mientras que el verbo que se situaba en el orden (d) después de este sintagma de $i d ̣ a ̂ f a$ adquiere la posición intermedia (entre al-mubtada' y el sujeto subordinado) en el orden sintáctico (c), cumpliendo la función de verbo de la oración verbal subordinada (atributo). De esta forma, a la hora de traducir este tipo de oraciones atributivas, optamos por el orden sintáctico (d), de acuerdo con las normas de construcción sintáctica del español, donde un orden de palabras de tipo (c) no tiene cabida.

Lo que hemos dicho acerca de las oraciones atributivas del orden sintáctico (c), es aplicable también a las compuestas cuyo atributo es una oración nominal subordinada, caso de la oración (29). Pero, en este caso, el fenómeno de inversión sintáctica afecta a una estructura que en origen es nominal o atributiva simple. En este sentido, esta última en su expresión más simple tiene el orden sintáctico (e) S(s. iḍāfa) $+\mathrm{AT}^{7}$ en que el sujeto es un sintagma de $i d \bar{a} f a$, que al formar parte de una estructura compuesta, lo que era su mudāaf ilayh (regido) se convierte en al-mubtad' de la oración compuesta, y lo que era al-muḍâf (regente) pasa a identificarse con al-mubtada' de la oración subordinada, mientras lo que era el atributo en la forma simple pasa, en la forma compuesta, a cumplir la función del atributo subordinado. Todos

\footnotetext{
${ }^{5}$ Este orden sintáctico es: sujeto + atributo en forma de una oración verbal subordinada y que se compone de verbo y un sujeto.

${ }^{6}$ Los elementos constituyentes de esta estructura sintáctica son: sujeto en forma de sintagma de iḍăfa un verbo.

${ }^{7}$ Los elementos constituyentes de este orden son: sujeto en forma de sintagma de $i \grave{d a} f a+$ atributo simple.
} 
estos elementos gramaticales forman en definitiva el orden sintáctico (f) $\mathrm{S}+\mathrm{AT}(\mathrm{s}+$ at) ${ }^{8}$.

Así, en lo que respecta la traducción de estas cláusulas atributivas compuestas, como hemos comprobado antes, sus equivalencias estructurales son las oraciones cuyo orden de palabras es del tipo (e), dado que en español optamos por el procedimiento de transposición, reflejado en el uso de los complementos preposicionales cuyos elementos constituyentes no se pueden invertir, tal como es el caso en la sintaxis del árabe. Así, no podemos traducir, la oración del ejemplo (29) por la primavera, su clima es moderado, puesto que el español no dispone de este orden sintáctico.

\subsection{Forma simple}

En cuanto a las oraciones atributivas en su expresión más simple, ha quedado claro que su traducción al español no plantea tantos problemas, como en los casos anteriores. Sin embargo, cuando el sujeto mubtada' o el atributo jabar de la misma tiene la forma sintáctica de un sintagma de $i d ̣ a f f a$, hay que tomar en consideración que, en la sintaxis española, los complementos preposicionales se construyen necesariamente mediante la preposición de que une a los dos nombres.

En cambio, en caso de que el atributo de una oración nominal es un sintagma de $i$ ịăfa formal, como en el ejemplo (17) que está formado por un núcleo de la categoría de un adjetivo indeterminado, antepuesto a un adyacente sustantivo. Este tipo de sintagmas, cuando se encuentra en función de atributo, se caracteriza por el hecho de que su regente (al-muḍăf) concuerda en género y número con el sujeto. Cosa que no tiene lugar en la lengua española, donde encontramos que los elementos de estos sintagmas se estructuran en función de un orden inverso: el adjetivo adquiere la posición sintáctica de un regente y el sustantivo la posición de un regido, precedidos ambos de la preposición de para formar todos un complemento preposicional en función de atributo. Así, como expone Paradela Alonso (2002: 37) a través del siguiente ejemplo: كلَّأصنْد قائي هُمْ طيبو القلب (35) (Todos mis amigos son de buen corazón).

A este respecto, hay que señalar también que muchos sintagmas de este tipo se utilizan en árabe para la expresión de un sentido figurado. Por consiguiente, cuando traducimos dichos sintagmas al español, utilizamos simplemente una palabra de la

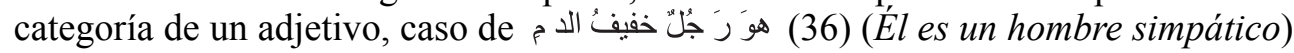
(Paradela Alonso 2002: 37).

Por otro lado, al igual que el caso de نं! -que como hemos señalado no se traduce- el pronombre $($ ouwa), cuando forma parte de una estructura atributiva no se traduce, puesto que su presencia en la oración se debe a razones de construcción sintáctica y no añade ningún matiz al sentido global del enunciado. Sin embargo,

\footnotetext{
${ }^{8}$ El orden sintáctico (f) lo forman los siguientes elementos: sujeto (mubtada') + atributo en forma de oración nominal subordinada.
} 
cuando al-jabar va definido, el papel de este pronombre resulta decisivo, puesto que cuando no aparece en este tipo de estructuras, éstas ya no son oraciones atributivas sino sintagmas compuestos de un nombre y un adjetivo. Recordemos la oración del ejemplo (33), en la que si suprimimos el pronombre separativo, la oración que resulta es: (37) El señor profesor. Es decir, las dos oraciones tienen un mismo sentido global, pero con la única diferencia de que en el primer caso se trata de una estructura atributiva cuyo jabar es determinado, mientras que en el segundo caso este mismo jabar pasa a funcionar como adjetivo por la ausencia del pronombre "huwa".

\subsection{Expresión temporal}

Como hemos venido explicando, a lo largo del desarrollo de este artículo, la traducción de los tiempos verbales de las estructuras atributivas y sus variantes con إن ان انَ del árabe al español puede plantear serios problemas. De esta manera, de acuerdo con nuestra hipótesis de partida, la oración atributiva árabe carece de un nexo verbal que indique la relación predicativa dada entre un sujeto y su atributo. No obstante, estas oraciones, en determinadas situaciones, aparecen formadas por el imperfectivo y el perfectivo del verbo كان . Esto no quiere decir que este verbo funciona como nexo verbal, sino que únicamente su uso viene impuesto por la necesidad de expresar los tiempos verbales de pasado y futuro.

Así, comprobamos que las oraciones atributivas del árabe, cuando carecen totalmente de un verbo, expresan un tiempo presente, como en la oración (1). En cambio, cuando las mismas expresan un tiempo pasado o futuro se les antepone respectivamente el perfectivo o el futuro de كانَ. Asimismo, hemos constatado que el tiempo verbal que corresponde en español al perfectivo es básicamente el pretérito imperfecto de ser o estar, por lo que las atributivas del español se caracterizan por un aspecto temporal durativo.

Por otra parte, donde los problemas de traducción de los tiempos verbales tienen todo su peso es cuando la oración atributiva del árabe se presenta bajo forma sintáctica de tipo (c) o (a). De este modo, cuando se les antepone el perfectivo o el imperfectivo de كان a estas estructuras, hay que tomar muy en consideración los diferentes matices temporales que resultan de la combinación del verbo subordinado con este "cancelador".

Por último, para concluir esta reflexión sobre la traducción en español de la oración atributiva árabe, hemos de resaltar un rasgo característico al que antes hemos aludido. Este rasgo consiste en el hecho de que en las oraciones atributivas del árabe no se expresan los matices de temporalidad e intemporalidad de las cualidades atribuidas al sujeto. En consecuencia, a la hora de traducir su expresión verbal, no hay que tomar tan sólo las diferentes perspectivas temporales de presente, pasado o futuro, sino que hay que tener en cuenta que, en español, las atributivas se construyen

9 Véase Paradela Alonso (2002: 79). 
con el verbo copulativo ser o estar en función de las características de dichas cualidades. Esta distinción, como hemos visto, no se hace en árabe, puesto que todas las cualidades (atributos) se expresan en los tiempos pasado y futuro con el mismo verbo (كان ). Por lo tanto, la única pista que resulta importante para el uso de ser o estar es la naturaleza del atributo que resulta de la traducción de la cualidad árabe, conforme a las normas de construcción de la atributiva española.

Ahora bien, hablando del uso del verbo copulativo, es preciso señalar que al igual que en las estructuras del orden sintáctico (a) y (c), donde utilizamos en su traducción un verbo predicativo, en la traducción de las oraciones atributivas del árabe, cuyo atributo es un complemento circunstancial (adverbio de lugar), el verbo correspondiente es también predicativo (estar) cuya función es indicar el lugar. Esto se debe a que la gramática árabe también incluye, dentro de las oraciones atributivas, las oraciones que expresan las nociones de lugar, como en las oraciones (32) y (33) y que suelen tener un atributo antepuesto al sujeto. Por esta razón, la equivalencia estructural de este tipo de atributivas al español es una oración predicativa cuyo orden sintáctico es sujeto + verbo + complemento (SVC), puesto que en esta lengua la noción de lugar se expresa mediante unas estructuras no atributivas.

\section{Práctica de traducción ${ }^{10}$}

Hālatā sars al-mu'akadatān al-latāni ḍaharatā fi ŷuzuri Bānjū dalīlun muzīrun l-lkalaḳī

Los dos casos confirmados de neumonía típica que han aparecido en las islas de Banjul es un motivo de preocupación

Huwa aḳallu adad yawmī munḍ 20 abrīl

Es el menor número diario desde el veinte de abril

Al-șin musta idatun li- ata āâwuni ma a al-muŷtama al-dawlī fì muhārabati sārs

China está preparada para colaborar con la comunidad internacional en la lucha contra la neumonía típica

Naḥnu musta idūna liż̇iyādati ta` āwunanā ma a rusyā wa al-muŷtama al-dawlī bi ashiri li-wiḳāyati min sārs

Nosotros estamos preparados para incrementar nuestra colaboración con Rusia y toda la comunidad internacional para prevenir la neumonía típica y curarla

Kāna sababan fi itlāḳi al- 'ināni li-nasā’imi al-ḥurriyati wa al-ta'bīri lada al- 'āmati mina al-nāsi

Era la causa de que la gente ignorante de rienda suelta a los aires de la libertad y la expresión

Kāna ḥaḳan muzīran wa muḍhilan

Era una verdad emocionante y sorprendente

${ }^{10}$ Los ejemplos de las oraciones atributivas árabes son sacados de las fuentes primarias indicadas al final del artículo. 
Kāna sāeidan fi al- i’ lāmi al-rasmī

Era predominante en la información oficial

Bāwadiruhu kānat wāḍihatan

Sus síntomas eran claras

Innanā samaḥnā biḳatli al- 'ajari

Hemos permitido matar a la otra persona

Kānati al-nusuru tuhalliku bikazratin fi samāe al-hind

Las águilas revoloteaban, con frecuencia, en el cielo de India

Huwa amrun gayru ' $\bar{a} d \bar{\imath}$

Es un caso insólito

Būtin Kāna mustaŝāran li-ŝarikati tabyī ḍi al-amwāl li-lmāfyā al-rusiya

Putín era consejero de una compañía que blanqueaba el dinero para la mafia rusa

Kāna ḥattā māris 2000 'uḍwan fi mầlis ŝarikatin almāniya

Era, hasta marzo de 2000, miembro del consejo de una compañía alemana

Kānati al-ŝrta al-ŷinā'iya al-fidirāliya al-almāniya tațarraḳat al-zulazā'al-māộ̀ ilā al'anŝitati al-maŝbuhati li-hāḍihi al-ŝarikati

La policía Anticrimen de Alemania Federal habló, el martes pasado, de las actividades sospechosas de esta compañía

Al-ŝarika al-mu ayyana hiya al-ŝarika al-rusiya al-almāniya

La compañía designada es la Compañía Ruso-alemana

Fladimīr smirnōf kāna musāe idan li-al ra ${ }^{e} \bar{i} s$ al-rūs $\overline{1}$

Fladimir Samironov era ayudante del presidente ruso

Kāna mudīran li- 'ahadi furū'i al-ŝarika

Era director de uno de las filiales de la compañía

Al-siyāsiyūna yakdibūna dā'iman

Los políticos mienten siempre

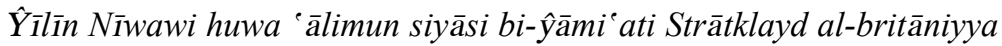

Gelín Niowe es un científico político en la Universidad británica de Strazclayd

Al-sababu al-ra'īsi li-lka'ḍib huwa iżdiyād takassi al-nās 'an al-hakika

El motivo principal de la mentira es la averiguación de la verdad por parte de la gente

Al-hadafu al-ra'̄isi mina al-barnāmaŷi huwa al-kiyāmu bi- 'amaliyāti al-baḥzi wa altatwīri

El objetivo principal del programa es efectuar las operaciones de investigación y desarrollo 
Al-kuwayt kānat awwala dawla tuḳaddimu musāe adatiha li-l'irāk

Kuwait era el primer país que prestaba sus ayudas y expertos a Irak liberado

Inna haḍa al-muḳarrar yaḳumu 'alá tahkiki garadhayni

Este programa tiene como fin conseguir dos objetivos

Dālika huwa al-nidhāmu al-ma 'mulu fi binā ${ }^{e}$ al-manāhiŷi al-dirāsiya li-al-duali almutaḳadima

Aquél es el régimen adoptado en la elaboración de los métodos educativos en los países desarrollados

Satakūnu al-kutubu ŷāhiżatan fi bidāyati al- 'āmi al-dirāsi

Los libros estarán disponibles al comienzo del año escolar

Haḍihi al- 'amwālu maṣdaruhā arṣida 'irāḳiya muŷammadatun fi al-wilāyāti almuttahida

El origen de este dinero es unos fondos iraquíes bloqueados por Estados Unidos

Kānat al-yābānu ḳad a'lanat ragbatahā fi tstidhāfati mu'tamari al-mutabarri īna aldawliyīna

Japón había expresado su deseo de acoger una conferencia internacional de donantes internacionales

Kāna Mūsa waṣala ilá San' ā’ ams

Musa había llegado a Saná anoche

Al-'intihāriyuna 'alá șila bi-maŷmu at "al-șirāt al-mustaḳim”

Los suicidas están relacionados con el grupo "Buen camino"

Al-dār al-baydhā' madina ma 'rufa bi-tasāmuhiha wa tanawwu'iha al-ddīn̄i

Casablanca es una ciudad muy conocida por su tolerancia y su diversidad étnica y religiosa

Alharbu 'alá al-irhāb mustamirratun

La Guerra contra el terrorismo está persistente

Al-magribu ṣad̄̄kun muḳarrabun li-alwilāyāti al-muttahida

Marruecos es un amigo cercano de Estados Unidos

Haḍā al-'iŷtimāe u huwa al-zāni li-baḥzi mawdhū'i naḳli maḳarri al-hay'ati al-'istizmāriya

Esta reunión es la segunda para discutir el traslado de la sede de la Consejería

Al-yamanu yuŝakkīlu ḥukumatan ŷadìtatan

Yemen forma un Nuevo gobierno

Kānat Ummatun ta'malu safira li-lyaman fi-hūlanda

Umma trabajaba como embajadora de Yemen en Holanda 
Huwa awwalu ra'ī amarīkī fi tāriji al-wilāyati al-muttahida yatawallá al-ri'āsa ba da istikala wa laysa wāfati ra'īs

Él es el primer presidente norteamericano en la historia de Estados Unidos, que se encarga de la presidencia después de una dimisión y no la muerte de un presidente biya

Al-jalāyá al-nā'ima is țilāḥun atlaḳahu al-'i lāmu al-garb̄̄ 'alá al-tandhīmāti al-’irhā-

"Células durmientes" es el término con el cual la información occidental califica a las organizaciones terroristas

Haḍihi al-jalāyā mizlu al-fitna

Estas células son como el tumulto

Haḍā al-'amru kad yastgriḳ waḳtan tawīlan

Este asunto puede ocupar mucho tiempo

Kānat ŷarīmatu al-ddāri albaydhā'hiya al-ūlá min naw'ihā fi al-mamlaka al-magribiya El crimen de Casablanca era el primero de este tipo en el Reino de Marruecos

Kāna haḍa 'ftirādhan gayra ṣahịhin

Esto era una suposición incorrecta

Kāna haḍā al- 'i tikāâu sababan fi al-'istirjā'al-amnī

Esta convicción era un motivo de la relajación policial

Al-ŷihatu al-hukūmiyatu al-'ujrá [...] hiya wiżāratu al-'ielām

La otra institución gubernamental [...] es el Ministerio de Información

Inna wiżārata al-ddājiliya mutālaba [...] bibaci 'uyūnihā fi al-maḳārri al-'intijābiya

El Ministerio de Interior está obligado, en estos días, a introducir sus vigilantes y sus servicios secretos en las sedes electorales

Inna al-ta'ȳida naw'ani

El apoyo es de dos tipos

Kāna sbārtā al-fariḳ al-dhayf

Sparta era el equipo visitante

Ramaḍān mutafā'il

Ramadan está optimista

Al-fawżu huwa al-’awwalu li-murismu 'alá sirinā

La Victoria de Morismo es la primera sobre Sirena

Al-fawżu tab à yahsimu al-ma rakata

La victoria, ciertamente, resuelve la batalla

Hiya al-marra al-zāliza al-llatī tablugu fihā Murīsmū al-mubārāta al-nihā'iya

Es la tercera vez en que Morismo llega a la final 
Al-muŝskila al-llatī nuwāȳ̄huhā [...] hiya giyābu kullu min ḥamāda yūsuf wa 'umar wa 'abdah

El problema con que nos enfrentamos [...] es la ausencia, tanto de Humada Yusuf como de Amru y Abad

Inna Farīkahu la ỉa mubārā ŷayyida

$\mathrm{Su}$ equipo ha jugado un buen partido

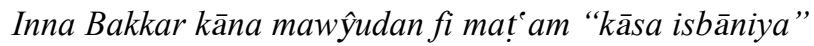

Bakkar estaba presente en el restaurante Casa España

Inna ḳișșata wuṣūlihi ilá haḍihi al-marḥala ḳiṣṣa muzīra

La historia de su llegada a esta fase es emocionante

Muhimmatu al-difāe satakūnu șa ba

La misión de defensa será difícil

Al-'āhābu kawādiruhā musta idda

Los militantes de los partidos están preparados

Al-insānu kazīru al-haraka

El ser humano es muy dinámico

Al-ddu ūsu mawdhū $\bar{a}$ tuhā mujtalifa

Los temas de las clases son diferentes

Kāna raŷulan nażīhan

Era un hombre honesto

Tikniyātu al-żirāe a hiya muta addida

Las técnicas de siembra son diversas

Al-wsūl ilá ittifākịin sayakūnu șa ban

LLegar a un acuerdo será difícil

Al-magrib fi tilka al- 'usuri kāna yuṭlaḳu alá tilka al-'aḳtār al-'arba a al-wāḳi a garba ŝamāl afrīkyā

Con "Marruecos" se denominaba, en aquellas épocas, a las cuatro regiones situadas al noroeste de África

Haḍihi hiya al-hudūd al-magribiya al-kadīma

Éstas son las fronteras antiguas de Marruecos

Al-sultān Mawlāy abdel'ażīż pulida sanat 1298 hî̀riya

El monarca Mulay Abdelaziz ha nacido el año 1298 de hégira

Huwa 'ibn al-sultān mawlāy al-hasan

Él es el hijo del monarca Mulay Al-hasan 
Kāna sinnuhu lā yataŷāważ 13 sana

$\mathrm{Su}$ edad no superaba 13 años

Mawt 'ahmad ban mūsa yu tabar al-ṣadma al-'ajīra al-latī kaḍafat bi-lmagrib ilá bu'rat al-'ihtilāl al-'aŷnabī

La muerte de Ahmad Ben Musa se considera como la última sacudida que arrojó a Marruecos al foco de la ocupación extranjera

Inna kazī an mina al-nāsi yūṣūna ḳabla mawtihim bi- 'an ŷudfanū ŷiwāra ḍālika al-dharih Mucha gente testa, antes de su muerte, ser enterrada cerca de aquel mausoleo

Haḍihi al-ḳabā'il al-latī kānat tud ā al-rīf al-wusṭá hiya banu waryāgal

Estas tribus que se llamaba el Rif son Banuwaryagal

Kāna haḍa al- abdu kinnan mamlūkan

Este siervo era un esclavo poseído

Hum musallahūna bi- 'ŷwadi al-banādiki

Ellos están armados con mejores rifles

Min asbābi tagayyuri al-mawākifi 'awdatu al-gużāti

Uno de los motivos del cambio de posturas es la vuelta de los invasores

Fa-al'atibbā'u wa al-ṣyādilatu al- 'arab kānu ŷasadan wāhidan

Los médicos y farmacéuticos árabes eran uno solo

Naḥnu nu'ayyidu baladanā fi waḳti al.harbi

Nosotros apoyamos nuestro pueblo en momentos de guerra

Huwa muhimmun ŷiddan

Es muy importante

Al-ḥuwātu al-'amrīkiya wa al-britāniya ustuḳbilat ka-ḳuwwati ị̂tilāl

Las fuerzas angloamericanas se han recibido como fuerzas de ocupación

Inna al-ta 'ŷ̄la min șa'nihi iḍhābu hamāsati aglabi al-ŝabābi

El aplazamiento puede privar a la mayoría de los jóvenes de su entusiasmo

Kullu haḍihi al-'iŝkāāâti [...] tanāwalathā al-ṣuhufu al-wataniya

Todos estos problemas [...] han sido abordados por la prensa internacional

Hiya insānun kāmilu al-'ahliya

Ella es una persona completamente cualificada

Al-'ālamu ḳaryatun șagīra

El mundo es un pañuelo

Inna al-mudīra turīdu izārata mawdhū'i al-juțta bayna al-fi'a wa al-'ujra

La directora quiere poner de manifiesto la cuestión del plan de vez en cuando 
Mustajdamū itissālāti al-magrib yunaddidūna bi-siyāsati "ṣammi al-'aḍāni” al-latiī tanhâyuhā al-'idāra

Los empleados de Itisalat Al- magreb denuncian la política de "oídos sordos" adoptada por la administración

Innahā 'idāratun șammā' bakmā',

Es una administración sorda y muda

Hiya mahaț al-nadhar fi warakti al-'imtihāani

Ella es el punto de mira en la hoja del examen

Inna fi al-ț̣āliba fi ba dhi al-'ahyāni yansāḳu ma a bardhi al-kalimāti

El estudiante, a veces, se despista con algunas palabras

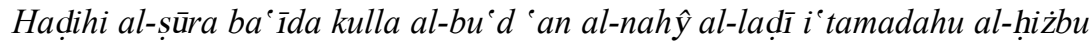

Esta imagen está lejos e la política adoptada por el partido

Fa- altarbiya manāhi ŷuhā tata?addadu

Así, los métodos educativos varían

Al-ŷawwu tajtalifu ta'ziratuha ḥāsaba al-fușūli

Las influencias del clima difieren según las estaciones

Kānat al-zawra kabīra

La revolución era grande

Al-ddurūsu mufída

Las clases son útiles

Inna al-ḥarba kābussun mudammirun

La Guerra es una pesadilla demoledora

Al-'iḥtîyâŷātu kānat mutawāṣila

Las protestas eran continuas

\section{Conclusión}

A modo de conclusión del presente artículo, podemos afirmar que la tarea de traducir al español la oración atributiva árabe y sus variantes sintácticas con inna y kāna no carece de problemas y dificultades. Éstos, como hemos podido comprobar, son debidos a las peculiaridades sintácticas que caracterizan a dicha estructura árabe, lo cual, en definitiva, las opone radicalmente a la atributiva española y hace que su traducción pueda plantear problemas. Por consiguiente, respecto a nuestro objetivo de encontrar equivalencias estructurales de estas oraciones en español, hemos llegado a las siguientes conclusiones: 
1. La oración atributiva del árabe se traduce al español mediante una estructura atributiva únicamente cuando su atributo es un adjetivo, un sustantivo o una oración nominal subordinada;

2. En los demás casos, las estructuras correspondientes a la misma son oraciones predicativas.

\section{Referencias bibliográficas}

AL-SANŶURŶ̀ 'ABdelaZIZ, M., Al-naḥw al-kāmīl fi kawā'id al- luga al-'arabiya. El Cairo: ȳāmi'at Al-Qāhira 1976.

Asín Palacios, M., Crestomatía del árabe literal con glosario y elementos de gramática. Madrid: Corregida 1959.

Ballard, M., De Ciceron a Banjamin; traducteurs, traductions, reflexions. Lille: Presses Universitaires 1988.

Blanco, P., Grammaire arabe composée d'après les sources primitives, T.1. Beirut: Donat Vernier 1891.

CATFORD, J.C., Una teoría lingüistica de la traducción. Trad. de F. Rivera. Caracas: Ediciones de la Universidad Central de Venezuela 1970.

CoRriente, F., Gramática árabe. Barcelona: Herder 1988.

Cowan, D., Gramática de la lengua árabe. Madrid: Cátedra 1998.

Dıв, I., Al-qawā 'id al-'arabiya al-ŷadīda, T.5. Beirut: Dār Al-kitāb Al-lubnānī 1974.

García YeBra, V., En torno a la traducción. Teoría. Crítica. Historia. Madrid: Gredos 1983.

ḦASAN, A., Al-naḥw al-wāfî, T.1. El Cairo: Dār Al-ma‘ārif 1975.

HAwoOD, J.A. et al., Nueva gramática árabe. Madrid: Ediciones Coloquio 1992.

HuRTADO AlBIR, A., Traducción y traductología: introducción a la traductología. Madrid: Cátedra 2001.

IBRAHIM 'UBADA, M., Al-ŷumla al- 'arabiya: mukawwinātuhā-anwa 'uhā-tahlīluhā. El Cairo: Mactabat Al-ādāb (s.a).

Mounin, G., Los problemas teóricos de traducción. Madrid: Gredos 1977.

NiDA, E. / TABER, CH., The theory and practice of translation. Leiden: The united Bible Societies 1969.

Paradela Alonso, N., Manual de sintaxis árabe. Madrid: Ediciones de la Universidad Autónoma de Madrid 2002.

VAlero Garcés, C., Encuentros en torno a la traducción II: una realidad interdisciplinar. Alcalá de Henares: Servicio de Publicaciones de Universidad de Alcalá de Henares 1996.

Veccía Vaglieri, L., Gramática della lengua araba: complemento della morfología e sintassi. Vol. 2. Roma: Instituto per L'Oriente 1961.

\section{Fuentes primarias}

AL-LÛH, AL 'ARBĪ (1982), “Al- minhāl fĩ kifāh abtāl al-š”. Tetwān: Matābi“ Al-šuij.

AL-WATAN (05/04/2003), Kuwait.

AL-WATAN (19/05/2003), Kuwait.

AL-TAŶDID (06/04/2003), Marruecos.

AL-TAŶDID (08/04/2003), Marruecos.

IDEAL (18/11/2002), Granada, España. 